\title{
Sonographic Correlation of Fetal Foot Length as a Reliable Parameter for Estimation of Gestational Age in $2^{\mathrm{ND}}$ and $3^{\mathrm{RD}}$ Trimester
}

Shabana Anwar*
Bachelors of Medical Imaging Technology, Department of Allied Health Sciences, Superior College Lahore, University Campus, 17-KM Raiwaind Road, Kot Arain, Lahore, Pakistan

Fiza Ajmal

Bachelors of Medical Imaging Technology, Department of Allied Health Sciences, Superior College Lahore, University Campus, 17-KM Raiwaind Road, Kot Arain, Lahore, Pakistan

Fatima Tasneef

Bachelors of Medical Imaging Technology, Department of Allied Health Sciences, Superior College Lahore, University Campus, 17-KM Raiwaind Road, Kot Arain, Lahore, Pakistan

Areej Muneer

Bachelors of Medical Imaging Technology, Department of Allied Health Sciences, Superior College Lahore, University Campus, 17-KM Raiwaind Road, Kot Arain, Lahore, Pakistan

Ahmad Mughees

Bachelors of Medical Imaging Technology, Department of Allied Health Sciences, Superior College Lahore, University Campus, 17-KM Raiwaind Road, Kot Arain, Lahore, Pakistan

Wasim Sajid

Masters in Diagnostic Ultrasound, Lecturer, Department of Allied Health Sciences, Superior College Lahore, University Campus, 17-KM Raiwaind Road, Kot Arain, Lahore, Pakistan

Tuseef Ahmed

Masters in Medical Imaging Technology, Lecturer, Faculty of Allied Health Sciences, The University of Lahore, 1-KM Defence Road, near Bhuptian Chowk, Lahore, Pakistan

Rana Muhammad Athar Azeem Shams

Masters in Medical Imaging Technology, Lecturer, Department of Allied Health Sciences, Superior College Lahore, University Campus, 17-KM Raiwaind Road, Kot Arain, Lahore, Pakistan

Rana Muhammad Bakhtawar Khan Sajawal

Masters in Mathematics, Lecturer, Department of Allied Health Sciences, Superior College Lahore, University Campus, 17-KM Raiwaind Road, Kot Arain, Lahore, Pakistan

Amna Babar

Masters in Diagnostic Ultrasound, Lecturer, Department of Allied Health Sciences, Superior College Lahore, University Campus, 17-KM Raiwaind Road, Kot Arain, Lahore, Pakistan

Shafqat Rehman

Masters in Medical Imaging Technology, Lecturer, Department of Allied Health Sciences, Superior College Lahore, University Campus, 17-KM Raiwaind Road, Kot Arain, Lahore, Pakistan

\footnotetext{
Abstract

Objective: To sonographic correlation fetal foot length as a reliable parameter for estimation of gestational age in $2^{\text {nd }}$ and $3^{\text {rd }}$ trimester.

Study Design: An analytical cross-sectional prospective study was performed.

Settings: The study was performed in Meer Children and family clinic, Tajpora Lahore.

Period: An analytical cross-sectional study was conducted from 15 October, 2021 to 15 January, 2021.

Material \& Methods: The present study is conducted in the in the Meer Children and Family Clinic Tajpura Lahore .In pregnant women attending the OPD during $2^{\text {nd }}$ and $3^{\text {rd }}$ trimester for routine checkups. The present study done in 60 normal pregnant women who were sure about their last menstrual period, have regular
} 
menstrual cycle, not experienced any vaginal bleeding. Ultrasonographic fetal foot length measurements was done without previous knowledge of gestational age and then the gestational age confirmed by biparietal diameter, abdominal circumference and head circumference .

Results: The present study is conducted in 63 pragnent women between 15 to 35 weeks of gestational age attending the OPD for $2^{\text {nd }}$ and $3^{\text {rd }}$ trimester routine checkups the in the Meer Children and Family Clinic Tajpura Lahore. Sonographically we calculated foot length from 15 to 35 weeks of gestation. In our study to Early age at which fetal foot length could be seen and measured sonographically was found to be 15 weeks of gestation age. In 27 weeks of gestational age and mean foot length 83.67 with std. deviation 5.718 and std. Error Mean 720 and the mean value of foot length by gestational age is 93.33 with std. deviation and std. error mean 338.740 and 42.677 respectivly. Along with foot length bipraietal diameter(BPD),Abdominal circumference(AC),head circumference $(\mathrm{HC})$ also measured for comparison.

Conclusion: In the normal growing fetus the fetal foot length increases with increasing gestational age. Fetal foot length is a good parameter for gestational age especially in cases of femur achondroplasia, dolichocephaly or brachycephaly and in cases who are not sure about their L.M.P. Fetal foot length is used as an investigational implement to measured of gestational age in the late second and third trimesters of pregnancy. Fetal foot length was especially useful when other parameters did not correctly estimate gestational age, e.g., in cases of shortlimb dwarfism hydrocephalus or anencephaly.

Keywords: Gestational age, Fetal foot length, Ultrasonographically age estimation

DOI: $10.7176 / \mathrm{JHMN} / 93-04$

Publication date:September $30^{\text {th }} 2021$

\section{Introduction}

In obstetrical, the growing age of a fetus, normally found on the assume first day of the last normal menstrual cycle . in embryology, this term is access as gestation does not start till fertilization of an oocyte happen around the middle of the menstrual cycle. Traditionally, GA is measured using the first day of the last menstrual period (LMP), which suppose that ovulation occurs on day 14 of the menstrual cycle ${ }^{[1]}$

Accurate assessment of gestational in all is not possible infants which is newborn mostly when they are not well and need throughout care support. Gestational age is important for prediction of morbidity, mortality and further management. ${ }^{[2]}$ Ultrasonography may be used to estimate gestational age. Accurate determination of gestational age is become important later in pregnancy for the management of obstetrical conditions such as postdate pregnancy preterm labor,intrauterine growth restriction. ${ }^{[3]}$

In the First-trimester the best parameter is crown rump length to measuring the gestational age and its used whenever appropriate. The to early ultrasound with a crown-rump length is equal to at least 7 weeks (or $10 \mathrm{~mm}$ ) may be used to measure the gestational age. ${ }^{[4]} \mathrm{A}$ baby grow rapidly in the first trimester. In the $1^{\text {st }}$ trimester fetus begins to grow a brain and spinal cord, and the organs start to form. The heart of the baby's will also start to beat during the first trimester. Legs and arms start to bud in the first weeks, and in the end of eight weeks, toes and fingers start to form.

In the second and third trimesters, determination of gestational age is expert by measuring the abdominal circumference, head circumference femur length and biparietal diameter. These measurements are only as good as the quality of the images. Ideal imaging can be found difficulty in some clinical situations, such as abnormal lie in a late pregnancy when the head is deep in the maternal pelvis, or multiple gestation, maternal obesity in these conditions we use fetal foot parameter. ${ }^{[5]}$

The fetal lower limb start develops as an outgrowth from the distal body stalk of the embryo which is termed as "limb bud" up to 39 days post conception. As the fourth embryonic week ends, three regions develop in the limb bud corresponding to the thigh, leg, and foot. Within the fifth embryonic week, the lower limb bud develops a distinctive morphology with a flat ventral and rounded dorsal surface shaped like a paddle, called the "foot plate. The footplate of the lower limb then rotates inward, causing the flexor surface to obliquely face the median sagittal plane of the embryo.

When the embryo reaches a size of about $14 \mathrm{~mm}$, the foot has initially 3 and later primitive toe rays. These toe rays acquire clefts or notches between them and develop a primitive heel. In the starting of the $3 \mathrm{rd}$ month, the fetal foot is in equinus, adducted and supinated. During the middle of the $3 \mathrm{rd}$ month, the foot dorsiflexes at the Ankle.$^{[6]}$

Many fetal parameters are try out and found to be useful in determination the GA $(1,2)$. The most commonly used parameters for determination of GA are abdominal circumference (AC), head circumference (HC), crown-heel length (CHL), crown-rump length (CRL), head length, femur length (FL) and head length (HC) $(1,2,3,4)$. In this study we have eestimat the validity of fetal measurements like HC, AC, CRL, CHL and FL for gestational age ${ }^{[7]}$

Fetal foot length is a reliable parameter to estimate the gestational age in early stage of pregnancy. This parameter is compared with crown rump length and the correlation in between foot length and other fetal measurements is accurate. A specific ratio of Gestational age is used in this period. Gestational are are calculated by following formula $\mathrm{GA}=0.335 \times \mathrm{FT}+8.845$ (adjusted $R 2=0.816, P<0.001) .{ }^{[8]}$ However, abnormal foetuses 
with Short limb dysplasias,hydrocephalus and anencephaly it is difficult to assess to gestational age. Fetal foot has a predictable device of normal growth and it is short limbs dysplasia, from short limbs because of inherent factors or in utero growth retardation. ${ }^{[9]}$

All medical course of action have risk. But, there's no confirmation to show a prenatal ultrasound done properly will harm a to mother or her unborn child. Done completely means it's done by a physician or a completely trained technician, which is called a sonographer. In Ultrasound radiation is not used like x-rays which is used in other procedures do The quality of ultrasound (US) images for the obstetric examination is crucial for accurate biometric measurement. [11]

An ultrasound high-frequency sound waves is used to create an image of a growing baby, the mother's placenta, and uterus, usually during the second trimester. Very important diagnostic information of growing baby is provided by an ultrasound in which including confirming the gestational age and pregnancy; checking for congenital anomalies multiple pregnancies, monitoring fetal position problems with the placenta; level of amniotic fluid, fetal growth, and aiding in other tests.The different kinds of ultrasounds include transvaginal ultrasound, 3-D ultrasound, 4-D ultrasound, or fetal echocardiography.Ultrasound (US), a standard diagnostic implement to determine fetal abnormalities, is a direction dependent imaging modality, i.e. The appearance of image is highly influences by the position of the probe. Different View-dependent artifacts like shadows can block parts of the anatomy of interest and reduce the quality and functionality of the image. Views dependent artifacts can be minimized If multiple images of the same structure are acquired from different views. ${ }^{[12]}$

\subsection{Materials and Methods}

An analytical cross-sectional prospective study was performed. The study was carried out in Meer children and family clinic Lahore. This duration of the study was conducted from 15 October, 2021 to 15 January, 2021. Sonographically we calculated foot length from 15 to 35 weeks of gestation. In our study to Early age at which fetal foot length could be seen and measured sonographically was found to be 15 weeks of gestation age. In 27 weeks of gestational age and mean foot length 83.67 with std. deviation 5.718 and std. Error Mean -720 and the mean value of foot length by gestational age is 93.33 with std. deviation and std. error mean 338.740 and 42.677 respectivly. Along with foot length bipraietal diameter (BPD), abdominal circumference (AC), head circumference (HC) also measured for comparison.

\section{Results}

Sonographically we calculated foot length from 15 to 35 weeks of gestation. In our study to Early age at which fetal foot length could be seen and measured sonographically was found to be 15 weeks of gestation age. In 27 weeks of gestational age and mean foot length 83.67 with std. deviation 5.718 and std. Error Mean -720 and the mean value of foot length by gestational age is 93.33 with std. deviation and std. error mean 338.740 and 42.677 respectively. Along with foot length bipraietal diameter (BPD), abdominal circumference (AC), head circumference (HC) also measured for comparison

\section{Discussion}

Gestational age is a determine by the age of a pregnancy which is taken from the start of the woman's last menstrual period (LMP). Commonly used parameters for the assessment of gestational age In the second and third trimesters, fetal head, body. Most commonly used parameters in which include head circumference, biparietal diameter, Abdominal circumference, and femur length. In our study we want to interoduce a new parameter fetal foot length is a reliable parameter for the estimation gestational age.

This study was done on 63 women with normal singleton gestations having regular menstrual cycles and known LMP to find accuracy of ultrasound in estimation of gestational age by foot length. Fetal foot length is not currently used parameter for assessment of gestational age but we find gestational age with foot length which were seen similar to the gestational age with other parameters. Sonographically we measured foot length from 15 to 35 weeks of gestation. In our study earliest age at which fetal foot length could be seen sonographically was found to be 15 weeks of gestation age. In 27 weeks of gestational age and mean foot length 83.67 with std. deviation 5.718 and std. Error Mean -720 and the mean value of foot length by gestational age is 93.33 with std. deviation and std. error mean 338.740 and 42.677 respectively. Along with foot length bipraietal diameter(BPD),Abdominal circumference(AC), head circumference(HC) also measured for comparison. Mean abdominal circumference is 27.88, Mean biparietal diameter is 27.42 , head circumference is 26.83 and foot length by gestational age is 93.33. In 19 weeks of gestational age Mode fetal foot length $21^{\mathrm{a}}$, abdominal circumference is $19^{\mathrm{a}}$, biparietal diameter 26, head circumference is 29 and foot length by gestational age is $55^{\mathrm{a}}$. In 15 weeks of gestational Minimum value fetal foot length 15, abdominal circumference is 15, Mean biparietal diameter 15,head circumference is 0 and foot length by gestational age is 18 . In 36 weeks of gestational age Maximum value fetal foot length 3502 , abdominal circumference is 74, Mean biparietal diameter 36, head circumference is 37 and foot length by gestational age is 2736 
Dr. Yogesh Yadav et al. conducted studies on Fetal Foot Length for Assessment of Gestational Age in (2015). The present study was conducted in the Department of Anatomy, Santosh Medical College \& Hospital in coordination with the Department of Anatomy \& Radio diagnosis Department of L.L.R.M. The present study was conducted in 100 pregnant women between 15 to 36 weeks of gestation, attending the OPD for 2 nd and 3 rd trimester routine checkups. Sonographically foot length calculated from 15 to 36 weeks of gestation. In this study the early age at which fetal foot length could be seen. sonographically was found to be 15 weeks of gestation and mean foot length is $17.5 \pm 1.29$ and mean sonographic foot length at 36 weeks of gestation is 64.4 \pm 3.28 . Along with foot length femur length, abdominal circumference(AC), head circumference(HC) and biparietal diameter (BPD), is also calculated for comparison From regression analysis a strong significant relationship has been noticed between Gestational age and fetal foot length. ${ }^{[6]}$

Bushra Abdul Malik et al. conducted studies on Use of Foot Measurements as Sonographic Parameter for Estimation of Fetal Age in (4 December 2017). Descriptive quantitative cross-sectional study conducted in the ultrasound department at Alshaekh Mohammed Ali Fadol hospital in Omdurman locality. The study included 400 healthy Sudanese pregnant women whom in the 1st 2nd and 3rd trimesters of different parity and ages. They have regular menstrual cycle Ultrasonographic measurement of Full Foot Length1 (FFL1), Foot Full Length2 (FFL2), and Foot Full Width (FFW) of all pregnant women were done. Sonographically measured fetal foot from 14 to 40 weeks of gestation. the study Evaluate that the mean FFL1 was $58.7 \pm 12.9 \mathrm{~mm}$. The minimum measurement was $18.8 \mathrm{~mm}$, and the maximum was $89.1 \mathrm{~mm}$, while the mean value of F.L2 was $53.4 \pm 11.4 \mathrm{~mm}$, with minimum value $17.5 \mathrm{~mm}$ and maximum $81.7 \mathrm{~mm}$, and the mean FFW was $23.7 \pm 5.1 \mathrm{~mm}$, with minimum value $7.0 \mathrm{~mm}$ and maximum $38.0 \mathrm{~mm}$. : a strongly significant relationships were observed between (FFL1, FFL2, FFW) and gestational age. ${ }^{[13]}$

S Kopal et al. conducted studies on Fetal foot length throughout gestation in (2013). It was a longitudinal prospective study of patients between 16 and 40 weeks of gestation longitudinal foot length measurements obtained in 50 antenatal women were studied. There was strong correlation between foot length measurements and gestational age and could be linearly predicted (Foot Length $=-14.02+2.3609 *$ Gestational Age, R2 $=0.97, \mathrm{P}<0.001$ ). Foot length had better correlation with gestational age compared to other sonologic parameters such as BPD, HC, AC and FLwith Pearson correlation values of $0.94,0.936,0.951,0.96$, respectively (all $\mathrm{p}<0.001) .{ }^{[10]}$.

\section{Conclusion}

In the normal growing fetus the fetal foot length increases with increasing gestational age. Fetal foot length is a good parameter for gestational age especially in cases of femur achondroplasia, dolichocephaly or brachycephaly and in cases who are not sure about their L.M.P. Fetal foot length is used as an investigational implement to measured of gestational age in the late second and third trimesters of pregnancy. Fetal foot length was especially useful when other parameters did not correctly estimate gestational age, e.g., in cases of short-limb dwarfism hydrocephalus or anencephaly

\section{Conflict of interest}

No potential conflict of interest relevant to this article was reported.

\section{References}

1. Papageorghiou, A.T., et al., Ultrasound - based gestational - age es timation in late pregnancy. Ultrasound in Obstetrics \& Gynecology, 2016. 48(6): p. 719-726.

2. Chavan, N., et al., The Correlation of Foot Length and Gestational Age. VIMS Health Science Journal, 2019. 6(1): p. 14-16.

3. Pandey, V.D., et al., Fetal tibial and foot length for prediction of gestational age: An ultrasonographic study. Santosh University Journal of Health Sciences, 2018. 4(1).

4. Butt, K., et al., Determination of gestational age by ultrasound. Journal of Obstetrics and Gynaecology Canada, 2014. 36(2): p. 171-181.

5. Gupta, S., et al., Early second - trimester sonography to improve the fetal anatomic survey in obese patients. Journal of Ultrasound in Medicine, 2014. 33(9): p. 1579-1583.

6. Chikkannaiah, P. and M. Gosavi, Accuracy of fetal measurements in estimation of gestational age. Indian Journal of Pathology and Oncology, 2016. 3(1): p. 11-13.

6. Chikkannaiah, P. and M. Gosavi, Accuracy of fetal measurements in estimation of gestational age. Indian Journal of Pathology and Oncology, 2016. 3(1): p. 11-13.

7. Wong, H.S., A revisit of the fetal foot length and fetal measurements in early pregnancy sonography. International Journal of Women's Health, 2017. 9: p. 199.

8. Majmudar, D.K., C.V. Vaidya, and V.J. Sanghrajka, Accuracy of Foetal Foot Length and Femur/Foot Length Ratio in USG Estimation of Gestational Age.

9. Hebbar, S., et al., Fetal foot length throughout gestation: a nomogram. Sri Lanka Journal of Obstetrics 
and Gynaecology, 2013.35(2).

10. Wu, L., et al., FUIQA: Fetal ultrasound image quality assessment with deep convolutional networks. IEEE transactions on cybernetics, 2017. 47(5): p. 1336-1349.

11. Zimmer, V.A., et al., Multi-view image reconstruction: Application to fetal ultrasound compounding, in Data Driven Treatment Response Assessment and Preterm, Perinatal, and Paediatric Image Analysis. 2018, Springer. p. 107-116.

12. Pandey, V.D., et al., Fetal foot length for assessment of gestational age: A comprehensive study in North India. Sch. J. Appl. Med. Sci, 2015. 3(1C): p. 139-44.

13. Gameraddin, G., S. Salih, and M. Yousef, Evaluation of gestational age with fetal foot length using ultrasonography. Journal of American Science, 2014. 10: p. 5-7.

\begin{tabular}{|c|c|c|c|c|c|c|c|}
\hline & & & & Statistics & & & \\
\hline & & $\begin{array}{c}\text { Abdominal } \\
\text { Circumference }\end{array}$ & $\begin{array}{l}\text { Bi-Parietal } \\
\text { Diameter }\end{array}$ & $\begin{array}{c}\text { Head } \\
\text { Circumference }\end{array}$ & $\begin{array}{c}\text { Foot } \\
\text { Length }(\mathrm{cm})\end{array}$ & $\begin{array}{l}\text { Gestational } \\
\text { age(weeks) }\end{array}$ & $\begin{array}{c}\text { Foot length by } \\
\text { Gestational } \\
\text { Age }\end{array}$ \\
\hline$\overline{\mathrm{N}}$ & Valid & 63 & 62 & 58 & 63 & 63 & 63 \\
\hline & Missing & 0 & 1 & 5 & 0 & 0 & 0 \\
\hline & & 27.88 & 27.42 & 26.83 & 83.67 & 27.23 & 93.33 \\
\hline & & $19^{\mathrm{a}}$ & 26 & 29 & $21^{\mathrm{a}}$ & $19^{\mathrm{a}}$ & $55^{\mathrm{a}}$ \\
\hline & & 15 & 15 & 0 & 15 & 15 & 18 \\
\hline & num & 74 & 36 & 37 & 3502 & 36 & 2736 \\
\hline
\end{tabular}

One-Sample Statistics

\begin{tabular}{lr|r|r|r} 
& $\mathrm{N}$ & \multicolumn{1}{c}{ Mean } & \multicolumn{1}{c}{ Std. Deviation } & \multicolumn{1}{c}{ Std. Error Mean } \\
\hline Gestational age(weeks) & 63 & 27.23 & 5.718 & .720 \\
\hline Foot length by Gestational Age & 63 & 93.33 & 338.740 & 42.677 \\
\hline
\end{tabular}

\section{One-Sample Test}

\begin{tabular}{|c|c|c|c|c|c|c|}
\hline & \multicolumn{6}{|c|}{ Test Value $=2$} \\
\hline & \multirow[b]{2}{*}{$\mathrm{t}$} & \multirow[b]{2}{*}{$\mathrm{df}$} & \multirow[b]{2}{*}{ Sig. (2-tailed) } & \multirow{2}{*}{$\begin{array}{c}\text { Mean } \\
\text { Difference }\end{array}$} & \multicolumn{2}{|c|}{$\begin{array}{l}95 \% \text { Confidence Interval of } \\
\text { the Difference }\end{array}$} \\
\hline & & & & & Lower & Upper \\
\hline Gestational age(weeks) & 35.013 & 62 & .000 & 25.225 & 23.79 & 26.67 \\
\hline $\begin{array}{l}\text { Foot length by } \\
\text { Gestational Age }\end{array}$ & 2.140 & 62 & .036 & 91.335 & 6.02 & 176.65 \\
\hline
\end{tabular}



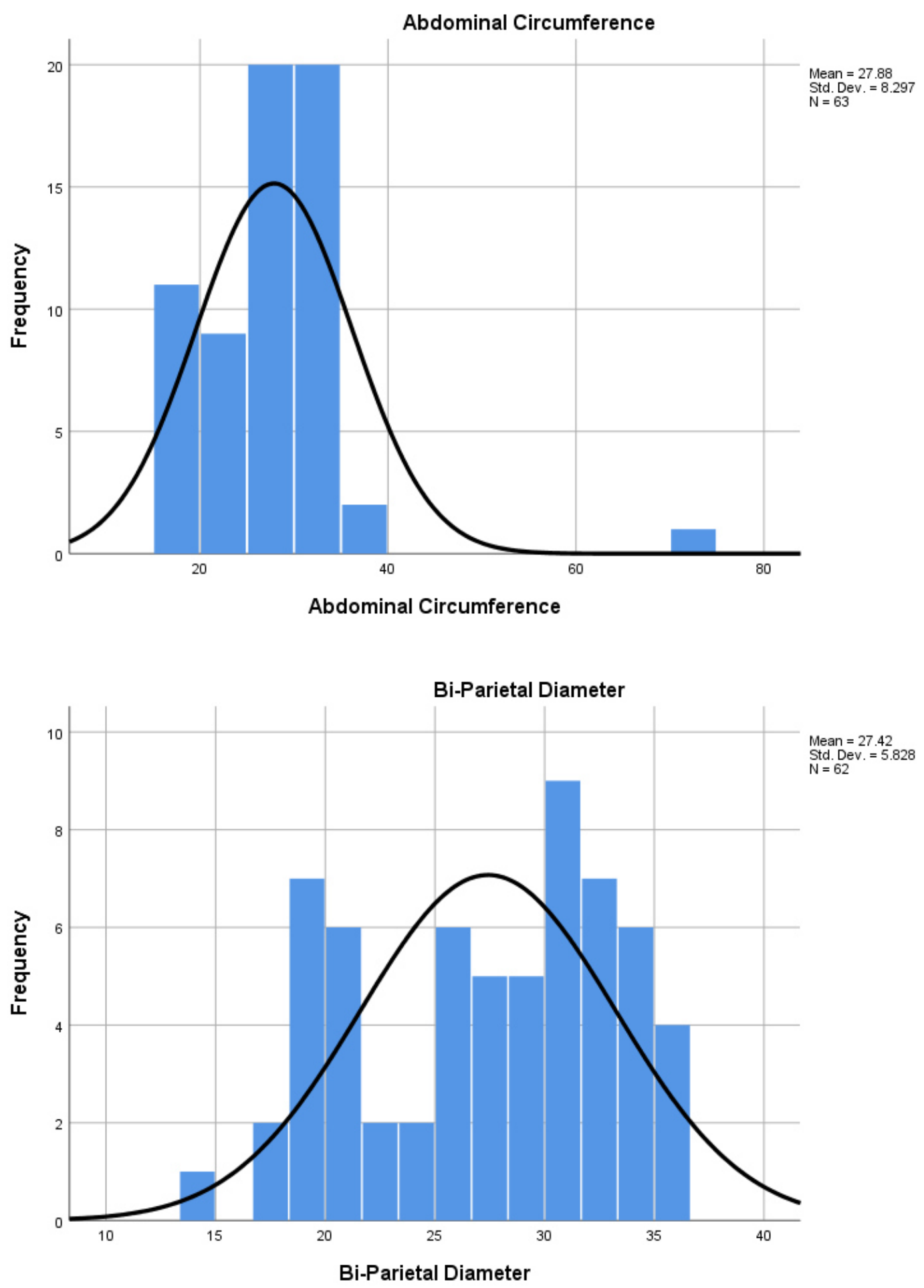

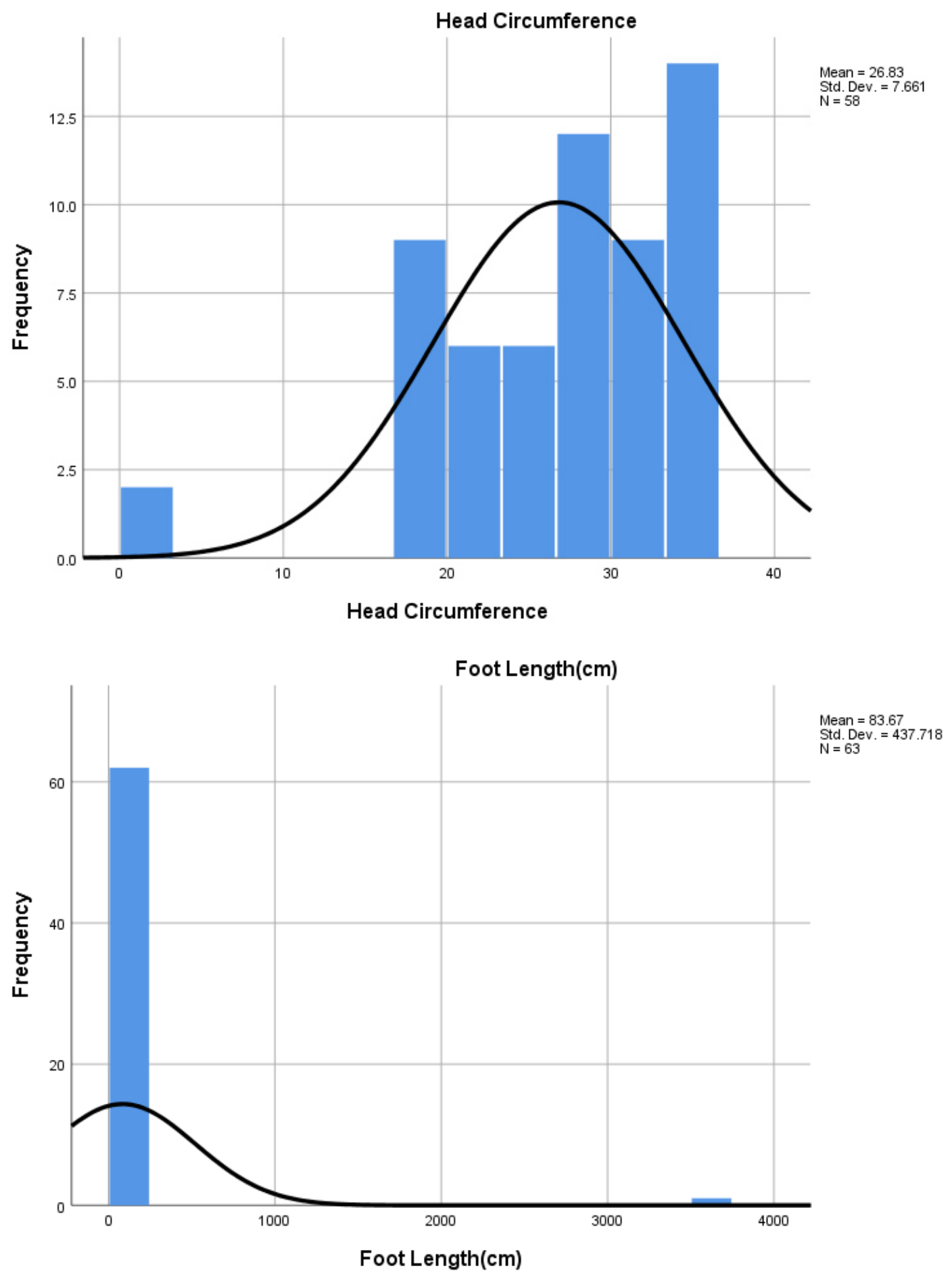